\title{
ANALISIS LOKASI PERSEBARAN IKAN DI LAUT SELATAN PULAU JAWA DENGAN MEMANFAATKAN DATA SATELIT ALTIMETRI
}

\author{
Ira Mutiara Anjasmara ${ }^{1}$, Risca Hartikasari ${ }^{2}$ \\ ${ }^{1,2}$ Departemen Teknik Geomatika, FTSLK-ITS, Kampus ITS Sukolilo, Surabaya, 60111, Indonesia \\ e-mail: ${ }^{2}$ riscahartikasari@gmail.com
}

\begin{abstract}
Abstrak
Indonesia yang merupakan negara maritim memiliki sumberdaya laut yang melimpah dan salah satunya adalah sektor perikanan. Sebagai salah satu sumber pangan dan penghasil devisa negara sektor perikanan membutuhkan teknologi yang mendukung dalam rangka memaksimalkan hasil dari sektor perikanan. Metode yang sudah ada adalah dengan memanfaatkan data citra satelit MODIS untuk memperoleh sebaran klorofil-a yang merupakan sumber makan bagi fitoplankton yang menjadi makanan ikan di laut. Parameter yang dibutuhkan untuk menentukan sebaran klorofil-a seperti sea surface height dan arus geostropik dapat juga diperoleh dengan memanfaatkan data satelit altimetri. Oleh sebab itu dalam penelitian ini dilakukan pengolahan data satelit altimetri untuk memperoleh parameter yang digunakan untuk menentukan perkiraan lokasi sebaran klorofil-a. Dari hasil pengolahan data diperoleh nilai hasil perhitungan berupa sea surface height (SSH), kecepatan arus geostropik dan arah arus geostropik di laut Selatan Pulau Jawa setiap bulan pada tahun 2016. Ketiga parameter tersebut kemudian dioverlaykan untuk menentukan perkiraan lokasi sebaran klorofil-a yang juga akan menentukan lokasi sebaran ikan.
\end{abstract}

Kata Kunci: Satelit Altimetri, Sea Surface Height, Arus Geostropik

\begin{abstract}
Indonesia which is a maritime country has abundant marine resources and one of them is fishery sector. As one source of food and foreign exchange earners, the fisheries sector needs supportive technology in order to maximize its potential. The existing method is to utilize MODIS satellite image data to obtain the distribution of chlorophyll-a which is a source of feeding for phytoplankton into fish food in the sea. Several parameters that are required to determine the distribution of chlorophyll-a such as sea surface height and geostrophic currents can be obtained by utilizing satellite altimetry data. Therefore, in this research, the data processing of altimetry satellite is used to obtain the parameters are used to determine the location of the chlorophyll-a. The processing result obtained the sea surface height (SSH), geostrophic current velocity and direction of geostrophic current in South sea Java every month in 2016. Those parameters then overlaid to analyze the areas that are predicted to be potential area of the distributions of chlorophyll-a that also determine the area of the fish's distributions.
\end{abstract}

Keywords- Altimetry Satellite, Sea Surface Height, Geostrophic Current 


\section{PENDAHULUAN}

Salah satu sumberdaya laut yang potensial di Indonesia adalah sektor perikanan. Selain sebagai sumber pangan bagi masyarakat Indonesia, sektor perikanan juga memberikan andil dalam menghasilkan devisa bagi negara. Pertumbuhan sektor perikanan sendiri terdiri dari berbagai jenis industri seperti perikanan budidaya, pengolahan perikanan, dan bioteknologi kelautan. Dimana potensi sumberdaya ikan lestari sebesar 6,4 juta ton per tahun yang 80 persennya merupakan jumlah tangkapan yang diperbolehkan. Produksi ikan sendiri bertambah dari 6,78 juta ton pada tahun 2006 dan menjadi 8,71 ton di tahun 2008 sehingga jumlah Unit Pengolahan Ikan meningkat dari $45 \%$ di tahun 2005 menjadi 55,2 \% ditahun 2008. Meskipun demikian Unit pengolahan Ikan di Indonesia masih jauh tertinggal apabila dibandingkan dengan negara-negara di kawasan ASEAN (ICCSR, 2010).

Untuk mendukung industri perikanan tangkap maka pengetahuan tentang lokasi di mana ikan-ikan berkumpul adalah faktor yang sangat penting. Lokasi ini merupakan daerah perairan dengan tingkat kesuburan tinggi yang ditandai dengan produktivitas primer. Makin tinggi produktivitas primer di suatu daerah maka tingkat kesuburan perairan tersebut makin tinggi pula. Produktivitas primer di suatu perairan dipengaruhi oleh tiga faktor, yaitu: cahaya, zat hara (nutrien), dan faktor oseanografi (ICCSR, 2010). Selain dipengaruhi faktor produktivitas primer faktor lainnya seperti suhu air laut dan arus laut juga mempengaruhi lokasi tempat hidup ikan (Kumaat, 2011).

Teknologi yang telah ada sebelumnya untuk menentukan lokasi persebaran ikan dengan memanfaatkan beberapa parameter seperti suhu permukaan laut, konsentrasi klorofil-a permukaan laut, anomali tinggi muka laut, angin, gelombang, dan arus. Dari berbagai parameter tersebut diperoleh dengan memanfaatkan teknologi penginderaan jauh dan satelit altimetri (BPOL, 2018). Dalam hal ini teknologi satelit altimetri dapat digunakan untuk memperoleh beberapa parameter yang mempengaruhi lokasi persebaran ikan. Sistem satelit altimetri berkembang sejak tahun 1975, saat diluncurkannya sistem satelit Geos-3. Pada saat ini secara umum sistem satelit altimetri mempunyai tiga obyektif ilmiah jangka panjang, yaitu : mengamati sirkulasi lautan global, memantau volume dari lempengan es kutub, dan mengamati perubahan muka laut rata-rata (MSL) global (Abidin, 2001).

Parameter yang dapat digunakan dari data satelit altimetri khususnya untuk memperoleh lokasi persebaran ikan yaitu arus geostropik dan tinggi muka laut/sea surface height (SSH). Dengan adanya arus geostropik akan dapat ditentukan apa yang disebut dengan fenomena arus eddy. Selanjutnya dari analisis arus eddy dapat menimbulkan dampak terjadinya fenomena upwelling dan downwelling sesuai arah yang ditimbulkan dan dilengkapi dengan analisis dari data pendukung yaitu tinggi muka laut. Sehingga dari berbagai parameter tersebut dapat dijadikan salah satu sumber untuk menentukan lokasi persebaran ikan di laut (Marpaung \& Prayogo, 2014).

Dalam penelitian ini, akan dilakukan suatu analisis untuk lokasi persebaran ikan di wilayah perairan Laut Selatan Pulau Jawa dengan melihat faktor arus geostropik yang didukung oleh faktor SSH. Selain kedua data faktor tersebut juga disertai dengan data pendukung berupa data suhu permukaan laut dan data persebaran klorofil-a di lokasi penelitian yang diperoleh dari Balai Penelitian dan Observasi Laut. Sehingga hasil akhir dari penelitian ini adalah suatu peta persebaran ikan berdasarkan analisis persebaran ikan di wilayah perairan Laut Selatan Pulau Jawa yang diperoleh dari data satelit altimetri.

\section{METODE}

Adapun metode yang digunakan dalam penelitian ini adalah sebagai berikut.

a. Langkah pertama yang dilakukan adalah melakukan akuisisi data dari satelit altimetri JASON-2 yang meliputi data bulan Januari - Desember 2016.

b. Setelah melakukan akuisisi data satelit altimetri, dari data tersebut kemudian dilakukan pengolahan untuk 
memperoleh data SSH dan kecepatan arus permukaan.

c. Proses pertama yang dilakukan yaitu dengan mengolah data altimetri untuk memperoleh data $\mathrm{SSH}$, langkah yang dilakukan untuk memperoleh data SSH adalah sebagai berikut (Eumetsat dkk 2017) :

i. Melakukan koreksi jarak dari data satelit altimetri.

ii. Koreksi jarak diperoleh dari $\mathrm{R}_{\text {corrected }}=\mathrm{R}_{\mathrm{Obs}}-\Delta \mathrm{R}_{\mathrm{dry}}-$ $\Delta \mathrm{R}_{\text {wet }}-\Delta \mathrm{R}_{\text {iono }}-\Delta \mathrm{R}_{\text {ssb }}$. (1)

iii. Setelah melakukan koreksi jarak, langkah selanjutnya dengan melakukan perhitungan $\mathrm{SSH}$ yang diperoleh dari $\mathrm{SSH}=$ AltitudeRcorrected.

d. Proses kedua yaitu perhitungan kecepatan arus geostropik dan arah arus geostropik. Langkah-langkah yang dilakukan adalah sebagai berikut (Harini, 2004):

i. Dari data satelit altimetri diperoleh parameter $\mathrm{u}$ dan $\mathrm{v}$ yang kemudian digunakan sebagai parameter untuk menghitung kecepatan arus geostropik dan arah arus geostropik.

ii. Untuk menghitung kecepatan arus geostropik adalah $V=\left(u_{s}^{2}+v_{s}^{2}\right)^{1 / 2}$

(2)

iii. Selanjutnya untuk menghitung arah arus geostropik dengan rumus $(180 / 3,14) \operatorname{atan} 2(u, v)$

e. Dari kedua proses tersebut yang berupa SSH dan kecepatan arus permukaan dilakukan overlay dengan ditambahkan data in-situ berupa suhu permukaan laut perairan Laut Selatan Pulau Jawa.

f. Dari hasil overlay semua data maka langkah selanjutnya dalah memetakan hasil overlay untuk untuk selanjutnya dapat dianalisa untuk mengetahui lokasi persebaran ikan di perairan Laut
Selatan Pulau Jawa. Analisa yang dilakukan berdasarkan kepada parameter yang yang digunakan yaitu dimana saat kondisi SSH rendah (negatif), kondisi termoklin positif, terjadi pertemuan antara fenomena upwelling dan downwelling, serta arus geostropik cukup kuat, maka berdasarkan beberapa parameter tersebut diprediksi menjadi lokasi dari keberadaan ikan.

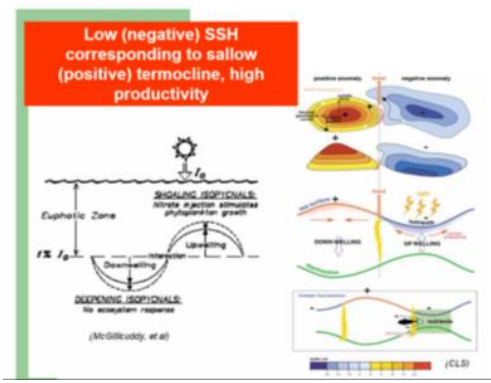

Gambar 1. Analisis Hubungan SSH dan SPL dengan Sebaran Ikan (Gaol, n.y.)

g. Dari hasil analisis kemudian dilakukan validasi dengan menggunakan data sebaran klorofil-a dari Badan Penelitian dan Observasi Laut.

h. Setelah dilakuan validasi lokasi potensi keberadaan ikan maka langkah terakhir yaitu membuat peta lokasi potensi persebaran ikan di perairan Laut Selatan Pulau Jawa

\section{HASIL DAN PEMBAHASAN}

Adapun hasil dari penelitian ini adalah peta prakiraan sebaran ikan berdasarkan prakiraan sebaran klorofil-a di Laut Selatan Pulau Jawa bulan Januari-Desember 2016.

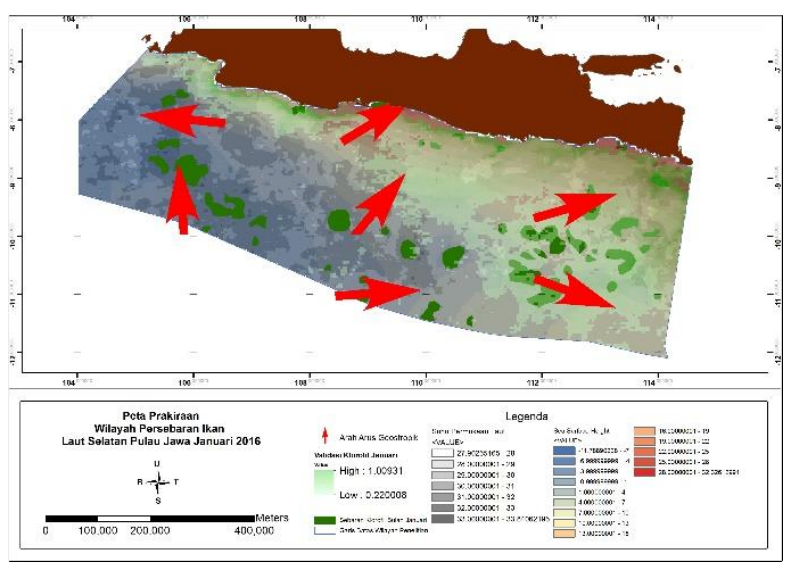

Gambar 2. Peta Sebaran Ikan Bulan Januari 2016 


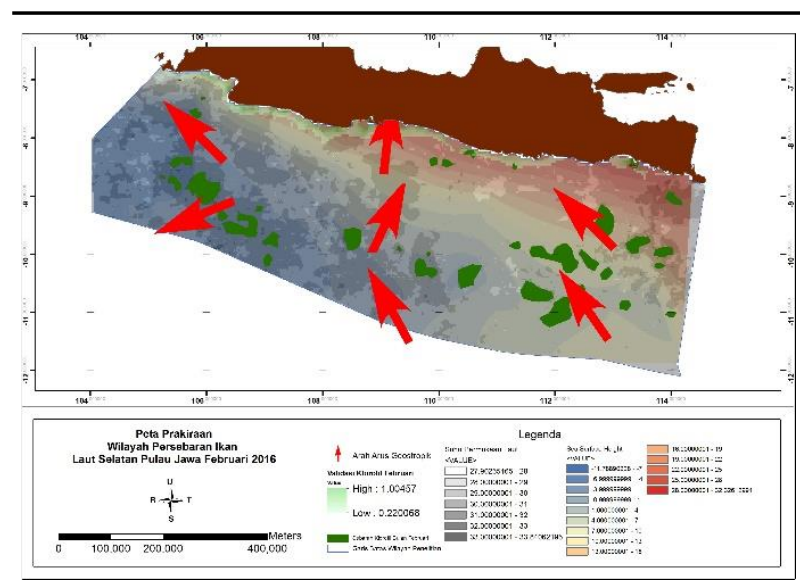

Gambar 3. Peta Sebaran Ikan Bulan Februari 2016

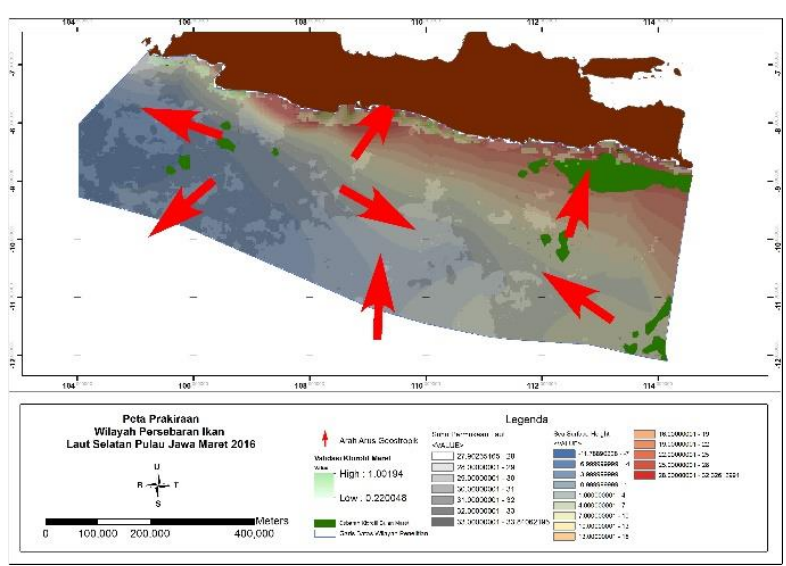

Gambar 4. Peta Sebaran Ikan Bulan Maret 2016

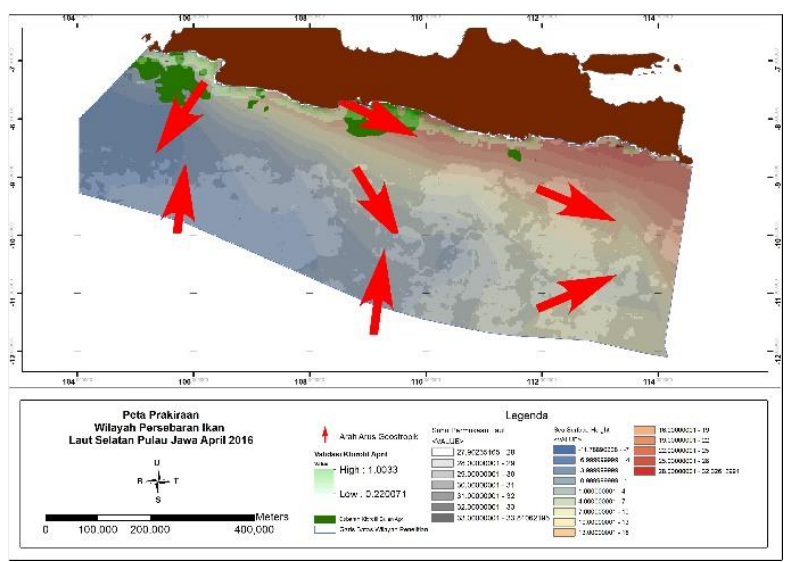

Gambar 5. Peta Sebaran Ikan Bulan April 2016
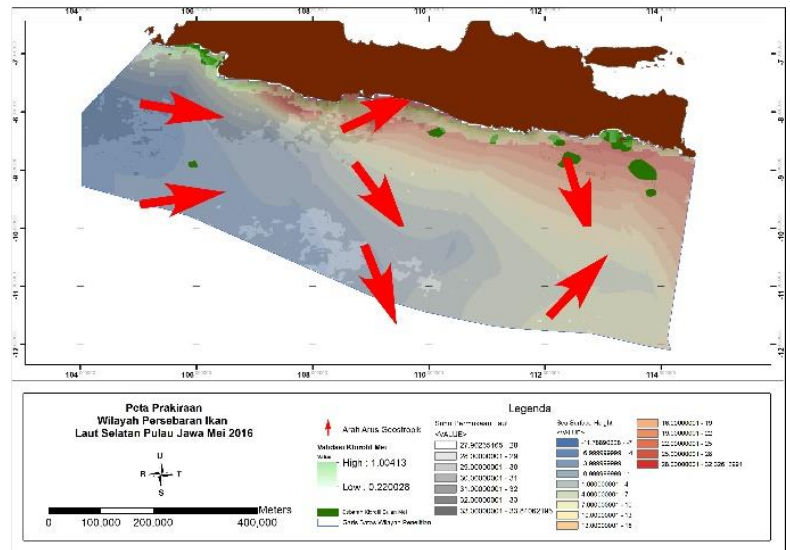

Gambar 6. Peta Sebaran Ikan Bulan Mei 2016

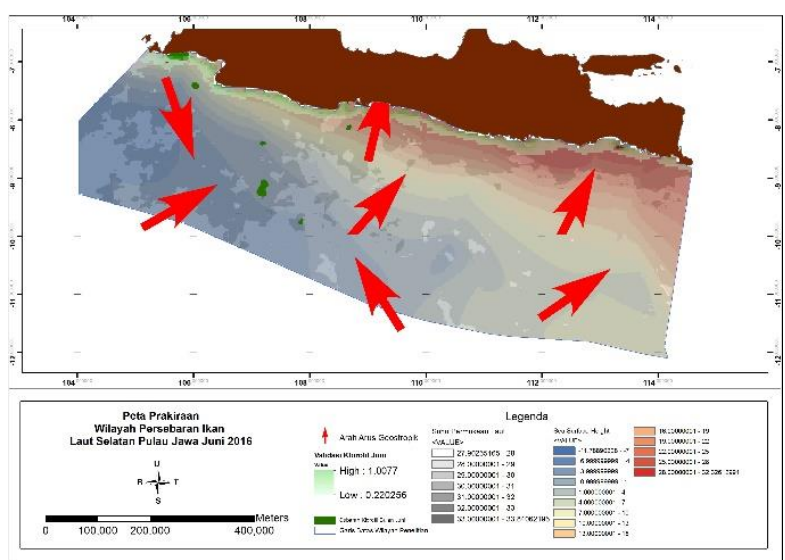

Gambar 7. Peta Sebaran Ikan Bulan Juni 2016

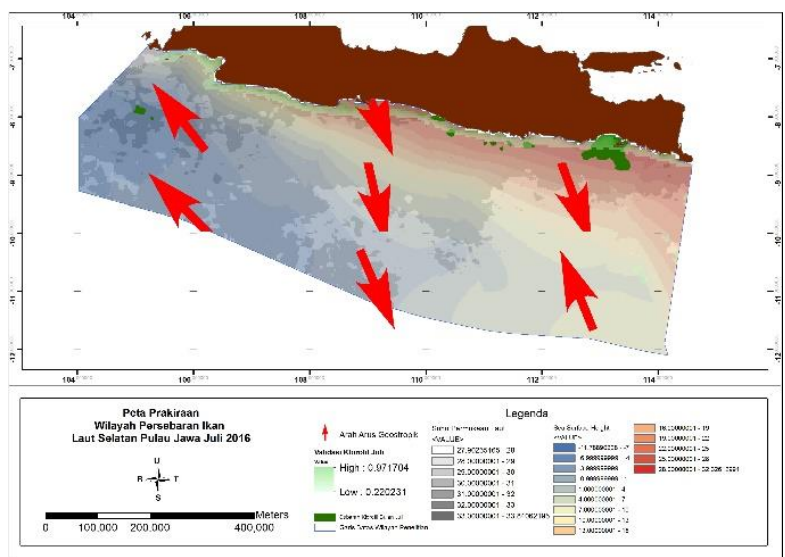

Gambar 8. Peta Sebaran Ikan Bulan Juli 2016 


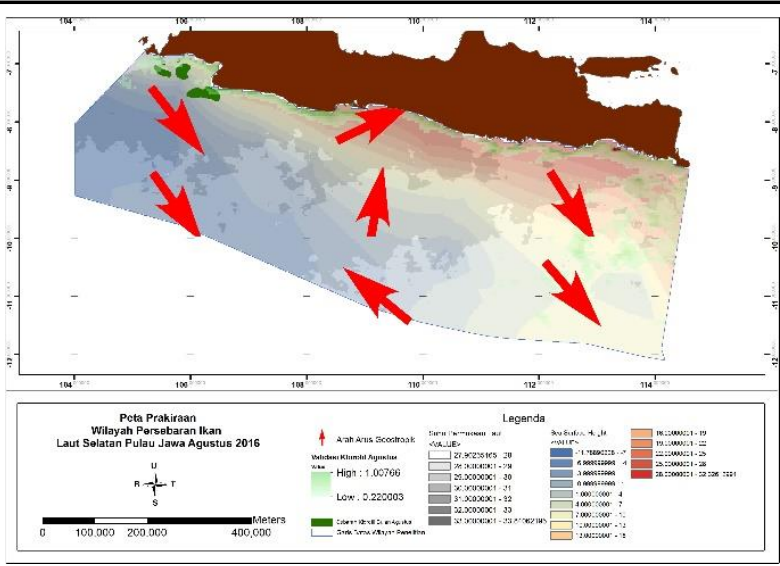

Gambar 9. Peta Sebaran Ikan Bulan Agustus 2016

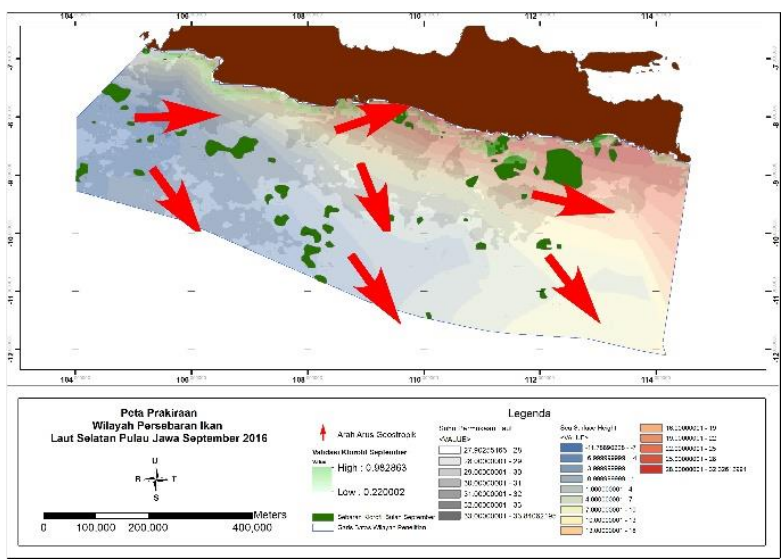

Gambar 10. Peta Sebaran Ikan Bulan September 2016

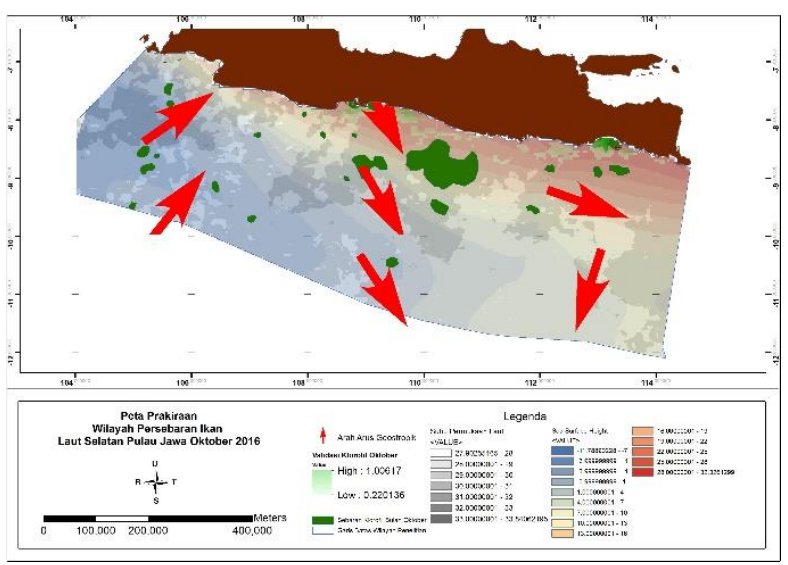

Gambar 11. Peta Sebaran Ikan Bulan Oktober 2016

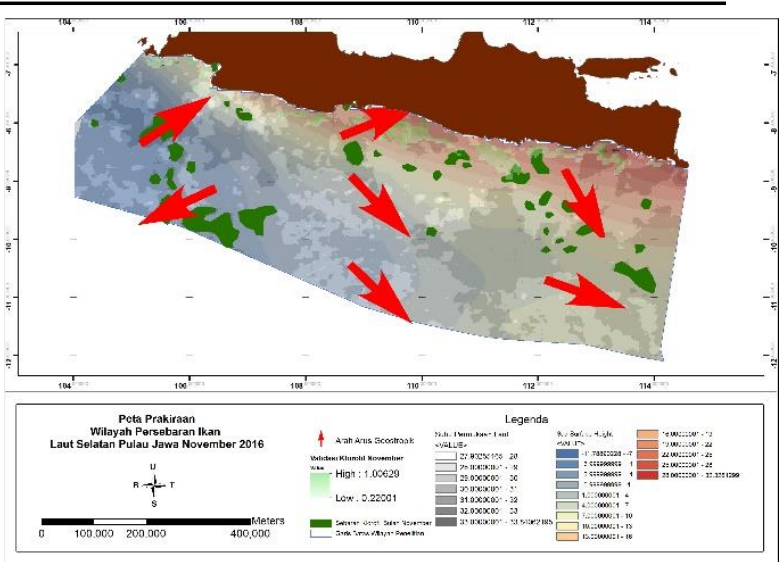

Gambar 12. Peta Sebaran Ikan Bulan November 2016

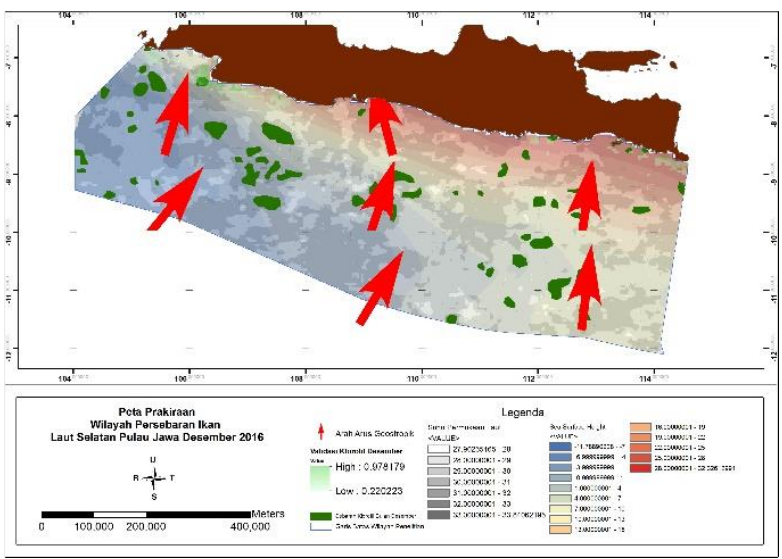

Gambar 13. Peta Sebaran Ikan Bulan Desember 2016

Dari perhitungan data satelit altimetri berupa sea surface height (SSH), kecepatan arus geostropik dan arah arus geostropik digunakan sebagai komponen untuk menentukan lokasi sebaran klorofil-a dan pola arus geostropik. Dari hasil perhitungan nilai sea surface height (SSH) setiap bulan yang ditampalkan dengan data suhu permukaan laut dari Badan Penelitian dan Observasi Laut diperoleh informasi berupa wilayah yang diperkirakan menjadi lokasi sebaran klorofil-a. Dari hasil prakiraan tersebut kemudian di validasi menggunakan data sebaran klorofil-a dari Badan Penelitian dan Observasi Laut. Setelah peta prakiraan yang ditampalkan dengan data validasi sebaran klorofil-a lokasi sebaran klorofil-a hasil prakiraan tidak seluruhnya menempati wilayah sebaran klorofil-a data validasi. Ketidaktepatan tersebut terjadi pada keseluruhan bulan yang diteliti. Sehingga daerah prakiraan dari data satelit altimetri kurang efektif apabila 
digunakan untuk menentukan wilayah sebaran klorofil-a yang menjadi tempat berkumpulnya fitoplankton yang merupakan sumber makanan utama ikan di laut.

\section{KESIMPULAN}

Kesimpulan yang diperoleh dari hasil penelitian ini adalah sebagai berikut :

a. Dari data satelit altimetri dapat diperoleh nilai hasil perhitungan berupa sea surface height (SSH), kecepatan arus geostrpik dan arah arus geostropik di laut Selatan Bulan Jawa setiap bulannya dimulai dari bulan Januari .hingga Desember 2016.

b. Pola arus geostropik di perairan Laut Selatan Pulau Jawa dapat diperoleh dengan melihat arah arus geostropik yang diperoleh dari parameter angina berupa komponen u dan v.

c. Pola sebaran ikan di perairan laut Selatan Pulau Jawa sejak Januari hingga Desember 2016 yang diprakirakan dari prakiraan sebaran klorofil-a hasil overlay nilai sea surface height dan suhu permukaan laut kurang efektif. Karena setelah Dilakukan proses validasi dengan data validasi sebaran klorofil-a Badan Penelitian dan Observasi Laut lokasi sebaran klorofil-a hasil prakiraan dari data satelit altimetri tidak seluruhnya cocok dengan data sebaran klorofil-a data validasi.

\section{UCAPAN TERIMA KASIH}

Penulis mengucapkan terima kasih pada Badan Penelitian dan Observasi Laut dan $\mathrm{AVISO}^{+}$yang telah memfasilitasi dalam penyediaan data.

\section{DAFTAR PUSTAKA}

Abidin, H. Z. (2001). Geodesi Satelit. (KARISTA, Ed.). Jakarta: PT Pradnya Paramita.

BPOL. (2018). Tim Peneliti Penginderaan Jauh Kelautan. Retrieved from http://www. bpol.litbang.kkp.go.id/old/ocean-remotesensing

Eumetsat, CNES, NASA, \& NOAA. (2017). Jason-2 Products Handbook (1 rev 1 ).

Gaol, J. L. (n.d.). Application of satellite altimetry for fisheries research. Chart, (1).

Harini, W. S. (2004). Pola Arus Permukaan Di Wilayah Perairan Indonesia Dan
Sekitarnya Yang Diturunkan Berdasarkan Data Satelit Altimetri TOPEX/POSEIDON. Institut Pertanian Bogor.

ICCSR. (2010). Sektor Kelautan dan Perikanan. (I. Mintzer, S. Thamrin, H. Von Luepke, \& T. Hertz, Eds.). Jakarta.

Kumaat, J. (2011). Pengaruh Faktor Lingkunga Pada Tingkah Laku Dan Kelimpahan Ikan.

Marpaung, S., \& Prayogo, T. (2014). Analisis Arus Geostropik Permukaan Laut Berdasarkan Data Satelit Altimetri. 